\section{PSYCHOLOGICAL WELL - BEING AMONG HIGH SCHOOL TEACHERS}

KEY WORDS: Psychological well being, Gender, Job Tenure and Type of Management.

\section{Ata. Sadaiah}

\section{Dr. Sylvia} Fernandez Rao
Research Scholar, Dept. of Psychology, Osmania University, Hyderabad- 500 007.

Scientist-'D', Assistant Director, Behavioural Science Unit, Extension and Training Divison, ICMR- National Institute of Nutrition, Jamia Osmania, Hyderabad.

An attempt was made in the present investigation Aim: psychological well - being among high school teachers. Objective: To assess the impact gender, job tenure and type of management on Psychological Well-Being among high school teachers. Sample: A sample consists of 1200 high school teachers from different government and private schools in erstwhile Warangal district of Telangana state. Tool: Psychological Well-Being Scale developed by Carol Ryff (1995) was used. Conclusions: Female teachers have high Psychological well being than the male teachers. Teachers with long job tenure have high Psychological well being than the teacher with short job tenure. Teachers working in government schools have high Psychological well being than the teachers working in private schools.

\section{INTRODUCTION}

Psychological Well-Being (PWB) is a state of well-functioning with an effective interpersonal skill and interaction with the members of society and work organization along with required energy and potential to cope with routine problems. Members of the society may include family, relatives, friends and any person in social contact. Members of the workgroup involve coworkers including superiors and subordinates. The routine problems may be concerned with routine matters of family, dealing with relatives and friends, performing well in the work organization, and the problems related with personal growth and development commonly faced by every individual. Persons with good Psychological Well-Being are better able to deal with these problems as compared with the persons with poor PsychologicalWell-Being.

It is the subjective feeling of contentment, happiness, satisfaction with life's experiences and of one's role in the word of work, sense of achievement, utility, belongingness, and no distress, dissatisfaction or worry, etc. These things are difficult to evaluate objectively, hence the emphasis is on the term "subjective" well-being. It may well be maintained in adverse circumstances and conversely, may be lost in favorable situation. It is related to nut not dependent upon the physical/physiological conditions.

\section{Review of Literature}

Merike Sisask et al., (2013) conducted to find out whether and how significantly teachers' satisfaction with school and their subjective psychological well-being are related to the belief that they can help pupils with mental health problems. Results revealed that Logistic regression models showed that better satisfaction with general school climate, higher psychological well-being, and the ability to understand pupils' mental health problems increased the odds of teachers' readiness to help pupils with mental health problems.

Zeenat Zahoor (2015) examined that the well-being of teachers affects the well-being of society tomorrow. Unless the well-being of individual teachers is improved, standards of education and that of the educational experience of young people will suffer with far-reaching financial, economic and social consequences for the nation. Significant differences emerged in the well-being and job satisfaction among government and private school teachers.

Lubna Jaffer Mansuri (2017) identified psychological wellbeing profiles in a sample of student- teachers from aided and unaided college of education. The results showed that a profile analysis shows a flat level of profile of the |www.worldwidejournals.com
Psychological Well-being of student-teachers of both the groups. The study reveals that there is no difference in the mean scores of psychological well-being of student teachers of both the groups of college of education.

Premila Chaudhari and Pragna Parikh (2019) showed that (1) there is no significant difference between the mean score of the psychological well-being among primary and higher secondary school teachers. Therefore it could be said that, the primary school teachers is having good psychological wellbeing than higher secondary school teachers, (2) there is no significant difference between the mean score of the psychological well-being among male and female school teachers and (3) there is no significant difference between interactive effect of the mean score of the psychological wellbeing among types of school teachers and gender.

Ioannis Katsantonis (2020) examined mainly the associations of contextual variables with stress and teachers' psychological well-being across organizational cultures. Structural equation modeling (SEM) was implemented to confirm the associations of protective factors with stress and workplace well-being at the individual unit of analysis. Results indicated that only a limited number of structural associations vary as a function of gender across all cultures at the individual unit of analysis. Mixed results were found in favor of within-cluster homogeneity of latent means.

Kannu Priya Kamboj and Pooja Garg (2021) found that from parallel multiple mediation indicate perseverance as a significant mediator and predictor of psychological wellbeing among factors of resilient traits, and self-reliance emerges as an inconsistent, yet significant mediator in the relationship between emotional intelligence and well-being of teachers. The direct effect of emotional intelligence on psychological well-being also emerged as statistically significant. Additionally, the female school teachers show higher emotional intelligence and resilience as compared to the male school teachers.

\section{Objective}

1. To assess the impact gender, job tenure and type of management on Psychological Well-Being among high school teachers.

\section{Hypotheses}

1. There would be significant impact of gender on PsychologicalWell-Being among high school teachers.

2. There would be significant impact of job tenure on PsychologicalWell-Being among high school teachers.

3. There would be significant impact of type of management 
on PsychologicalWell-Being among high school teachers.

Sample

A sample of 1200 high school teachers from different government and private schools in erstwhile Warangal district of Telangana state. The subjects were in the age group of 25-58 years selected and using systematic random sampling method.

\section{Variables Studied:}

\section{Independent Variables}

1. Gender (Male/Female)

2. Job Tenure (Short Job tenure / Long Job Tenure)

3. Type of Management (Government / Private)

\section{Dependent Variable}

1. PsychologicalWell-Being

\section{Tool}

\section{Assessment of PsychologicalWell-Being:}

Psychological Well-Being Scale developed by Carol Ryff (1995) was used. It contains 42 items with six areas i.e., Autonomy, Environmental mastery, Personal growth, Positive relations with others, Purpose in life and Self-acceptance. The reliability coefficient is reported to be 0.91 and the test-retest reliability is reported to be 0.86 .

\section{Statistical Analysis}

The obtained data were subjected to statistical analysis such as Means, SDs, and Analysis of Variance (ANOVA) were used.

\section{RESULTS AND DISCUSSION}

Table-i: Means And SDs For Scores On PsychologicalWell Being Among High School Teachers.

\begin{tabular}{|c|c|c|c|c|c|}
\hline \multirow{4}{*}{\multicolumn{2}{|c|}{\begin{tabular}{|l|} 
Type of \\
Management
\end{tabular}}} & \multicolumn{4}{|l|}{ Gender } \\
\hline & & \multirow{2}{*}{\multicolumn{2}{|c|}{\begin{tabular}{|l|} 
Male \\
Job Tenure \\
\end{tabular}}} & \multirow{2}{*}{\multicolumn{2}{|c|}{\begin{tabular}{|l|} 
Female \\
Job Tenure
\end{tabular}}} \\
\hline & & & & & \\
\hline & & $\begin{array}{l}\text { Short } \\
\text { Job } \\
\text { tenure }\end{array}$ & $\begin{array}{l}\text { Long } \\
\text { Job } \\
\text { tenure }\end{array}$ & $\begin{array}{l}\text { Short } \\
\text { Job } \\
\text { tenure }\end{array}$ & $\begin{array}{l}\text { Long } \\
\text { Job } \\
\text { tenure }\end{array}$ \\
\hline Government & Mean & 165.30 & 163.38 & 161.58 & 169.08 \\
\hline & SD & 23.77 & 21.27 & 23.27 & 17.35 \\
\hline Private & Mean & 161.18 & 165.18 & 164.50 & 166.58 \\
\hline & SD & 20.19 & 24.05 & 21.55 & 20.63 \\
\hline \multicolumn{6}{|c|}{ Grand Means } \\
\hline \begin{tabular}{|l} 
Male $=(\mathrm{M}$ \\
$: 163.76)$ \\
Female $=(\mathrm{M}$ \\
$165.43)$
\end{tabular} & & \multicolumn{2}{|c|}{$\begin{array}{l}\text { Short Job tenure }=(\mathrm{M} \\
: 163.14) \\
\text { Long Job tenure }=(\mathrm{M} \\
: 166.05)\end{array}$} & \multicolumn{2}{|c|}{$\begin{array}{l}\text { Government }=(\mathrm{M} \\
\text { 164.84) } \\
\text { Private }= \\
(\mathrm{M}: 164.36)\end{array}$} \\
\hline
\end{tabular}

A close observation of table-I shows that the female teachers with long job tenure of government schools obtained a high score of 169.08 indicates that their high Psychological well being compared to other groups. Male teachers with short job tenure of private schools obtained a low score of 161.18 that their low Psychological well being compared to other groups. In terms of gender, female teachers $(\mathrm{M}=165.43)$ have high Psychological well being than the male teachers $(M=163.76)$. In terms of job tenure, teachers with long job tenure $(\mathrm{M}=166.05)$ have high Psychological well being than the teacher with short job tenure $(M=163.14)$. In terms of type of management, teachers working in government schools $(\mathrm{M}=164.84)$ have high Psychological well being than the teachers working in private schools $(\mathrm{M}=164.36)$.

Table-II: Summary Of ANOVA For Scores On Psychological Well Being Among High School Teachers.

\begin{tabular}{|l|l|l|l|l|}
\hline Source of Variance & Sum of Squares & df & MSS & F-Values \\
\hline Gender (A) & 3291.063 & 1 & 3291.063 & $7.04 * *$ \\
\hline Job Tenure (B) & 2401.223 & 1 & 2401.223 & $5.13^{*}$ \\
\hline $\begin{array}{l}\text { Type of } \\
\text { management (C) }\end{array}$ & 3895.063 & 1 & 3895.063 & $8.34 * *$ \\
\hline A X B & 3120.063 & 1 & 3120.063 & $6.68 * *$ \\
\hline
\end{tabular}

\begin{tabular}{|l|l|l|l|l|}
\hline A X C & 2166.423 & 1 & 2166.423 & $4.64 *$ \\
\hline B X C & 3189.063 & 1 & 3189.063 & $6.82 * *$ \\
\hline A X B X C & 3928.223 & 1 & 3928.223 & $8.40 * *$ \\
\hline Within & 183157.580 & 392 & 467.239 & -- \\
\hline Total & 205148.701 & 399 & -- & -- \\
\hline
\end{tabular}

** - Significant at 0.01 level *-Significant at 0.05 level

Hypothesis-1: There would be significant impact of gender on Psychological well being among high school teachers.

As shown in table-II that the obtained ' $F$ ' value of 7.04 is significant at 0.01 level indicates that gender has significant impact on Psychological well being among high school teachers. As the ' $F$ ' values is significant, the hypothesis- 1 , which stated that gender has significant impact on Psychological well being among high school teachers, is not accepted as warranted by the results.

Hypothesis-2: There would be significant impact of job tenure on Psychological well being among high school teachers.

It is evident from table-II that the obtained 'F' value of 5.13 is significant at 0.05 level indicates that job tenure has significant impact on Psychological well being among high school teachers. As the ' $F$ ' value is significant, the hypothesis2 , which stated that job tenure has significant impact on Psychological well being among high school teachers, is accepted as warranted by the results.

Hypothesis-3: There would be significant impact of type of management on Psychological well being among high school teachers.

Table-II that the obtained ' $F$ ' value of 8.34 is significant at 0.01 level indicates that type of management has significant impact on Psychological well being among high school teachers. As the ' $F$ ' values is significant, the hypothesis-3, which stated that type of management has significant impact on Psychological well being among high school teachers, is accepted as warranted by the results.

As shown in table-VII data reveals that the 'F' values of 6.68 gender and job tenure (AXB); 4.64 gender and type of management (AXC), 6.82 job tenure and type of management (BXC) of first order interaction are significant. The ' $F$ ' value of 8.40 gender, job tenure and type of management (AXBXC) is significant at 0.01 level implied that there is significant interaction among three variables, gender, job tenure and type of management is causing the effect on Psychological well being.

\section{CONCLUSIONS}

1. Female teachers have high Psychological well being than the male teachers

2. Teachers with long job tenure have high Psychological well being than the teacher with short job tenure.

3. Teachers working in government schools have high Psychological well being than the teachers working in private schools.

\section{REFERENCES}

1. Ioannis Katsantonis (2020). Factors Associated with PsychologicalWell-Being and Stress: A Cross-Cultural Perspective on Psychological Well-Being and Gender Differences in a Population of Teachers.Pedagogical Research, 4(5), 1-12.

2. Kannu Priya Kamboj and Pooja Garg (2021). Teachers' psychological wellbeing role of emotional intelligence and resilient character traits in determining the psychological well-being of Indian school teachers. International Journal of Educational Management, 1-22.

3. Lubna Jaffer Mansuri (2017). A Profile of PsychologicalWell-being of Student: Teachers of Colleges of Education. An Int. J. of Education and Applied Social Science, 8, 309-314.

4. Merike Sisask et al., (2013). Teacher satisfaction with school and psychological well-being affects their readiness to help children with mental health problems. Health Education Journal, 73(45), 1-12.

5. Premila S. Chaudhari and Pragna Parikh (2019). Psychological Well-being among Primary and Higher Secondary School Teachers. The International Journal of Indian Psychology, 7(3), 1-6.

6. Zeenat Zahoor (2015). A Comparative Study of PsychologicalWell-Being and Job Satisfaction among Teachers. Indian Journal of Health and Wellbeing, 6(2), 181-184. 